Pure \& Appl. Chem., Vol. 49, pp. 1059 - 1067. Pergamon Press, 1977. Printed in Great Britain.

\title{
THE HYDROLYSIS OF PHOSPHATE ESTERS
}

\section{F. H. Westheimer}

Department of Chemistry, Harvard University, Cambridge, Massachusetts 02138 , USA

\begin{abstract}
The hydrolysis of a phosphate, phosphonate or phosphinate ester generally takes place either through a trigonal bipyramidal hydroxyphosphorane as intermediate (with expansion of the coordination number of phosphorus from four to five) or (at least for phosphates) through a monomeric metaphosphate as intermediate (with contraction of the coordination number of phosphorus from four to three). These processes parallel the principal mechanisms for the hydrolysis of carboxylic esters, which require either the formation of a tetrahedral intermediate or that of an acylium cation.
\end{abstract}

\section{INTRODUCTION}

The hydrolyses of phosphate esters parallel to a remarkable degree those of esters of carboxylic acids. The major pathway for the hydrolysis of an ordinary ester requires the formation of a tetrahedral intermediate; the major pathway for the hydrolysis of a phosphate, phosphonate or phosphinate ester requires the formation of a trigonal bipyramidal intermediate. Kinetics (1), isotope exchange (2) and other chemistry (3) provide evidence that a tetrahedral intermediate, as contrasted to a tetrahedral transition state, is required in the hydrolysis of a carboxylic acid ester; the evidence for a true intermediate in the hydrolysis of some phosphate esters, from kinetics, product formation and stereochemical studies is equally convincing.

A second mechanism for the hydrolysis of organic esters proceeds through acylium ions such as

$\mathrm{CH}_{3} \mathrm{CO}^{+}(4,5,6)$. A comparable mechanism for the hydrolysis of phosphate esters involves the intervention of monomeric metaphosphates, such as $\mathrm{CH}_{3} \mathrm{OPO}_{2}$ and $\mathrm{PO}_{3}^{-}$. Just as $\mathrm{nmr}$ spectroscopy has provided solid evidence for acylium ions, so several recent developments have provided evidence for monomeric metaphosphates.

\section{PHOSPHORANES}

Pnosphoranes from cyclic phosphates. Convincing evidence that trigonal bipyramidal structures are intermediates, rather than transition states, in the hydrolysis of cyclic phosphate esters was offered in 1966 (7). The hydrolysis of methyl ethylene phosphate occurs both with ring opening and with loss of the exocyclic methyl group (8); the rates for both processes are about $10^{6}$ times that for trimethyl phosphate. Hydrolysis of methyl butylphosphonate (9) occurs rapidly, but nearly exclusively with ring cleavage (7), whereas the hydrolysis of methyl tetramethylenephosphinate is slow. These facts could be reconciled (7) on the assumptions that (a) nucleophilic attack on an ester to form a phosphorane, and subsequent loss of a leaving group from a phosphorane, occur preferentially to and from apical positions of a trigonal bipyramid, (b) five-membered heterocycles containing phosphorus are strained (10), (c) when a phosphorane is formed as intermediate in hydrolysis, the strain is relieved by placing the small ring in one apical and one equatorial position, (d) in phosphoranes, the polarity rules are obeyed, e.g. electron withdrawing groups preferentially occupy apical positions, while electron donating groups preferentially occupy equatorial positions (11) (this rule has now been modified; see Trippett (12)). (e) The final assumption is that phosphoranes may undergo ligand reorganization ("pseudorotation") under the limitations of the strain rule and the polarity rule given above. For example, the exocyclic cleavage of methyl ethylene phosphate most probably occurs as follows: 

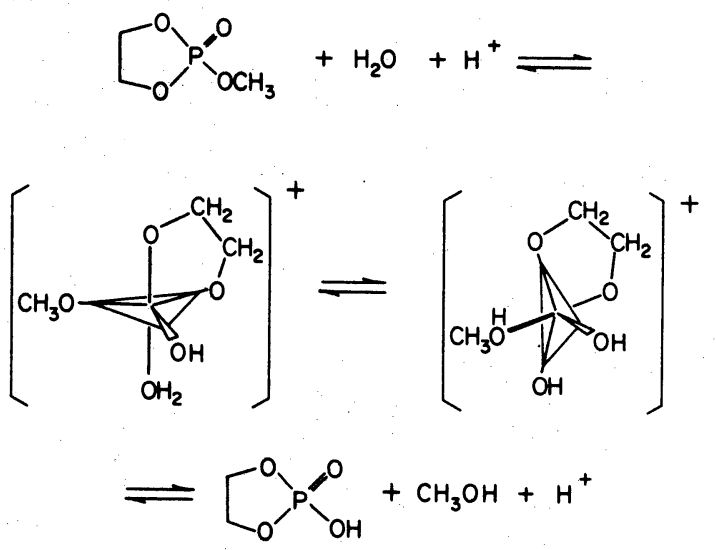

The general scheme, represented by the principles (a) - (e) above, and illustrated with the mechanism of hydrolysis of methyl ethylene phosphate, has proved to have considerable predictive capability, and has been verified by numerous investigators (13).

Acyclic aryl phosphates. The acid catalyzed hydrolysis of triaryl phosphates shows a maximum in the rate vs. acidity curve $(14,15,16)$. This maximum has been ascribed to the decrease in the activity of water with increasing concentration of acid.

The hydrolysis of amides shows a maximum rate at about $3 \mathrm{M}$ acid, and a decrease in rate at higher acidity; this decrease in rate has likewise been ascribed to a decrease in the availability of water at high acidity (17). But amides show a $\mathrm{pK}$ in the neighborhood of -1 to -2 , so that in acid more concentrated than $2 \mathrm{M}$ (where $\mathrm{H}_{0}<-1$ ) they are substantially protonated. A further increase in acid cannot cause much additional acid catalysis; consequently, the decrease in the activity of water that accompanies an increase in acidity can be responsible for a decrease in rate. However, the pK of triphenyl phosphate $(16,18)$ is probably around -5 , so that in the acidity range where $H_{0}>-3$, less than $1 \%$ of the ester is protonated. If the rate maximum, and fall in rate at high acidity, occurs because water is insufficiently available for hydrolysis, then a decrease in water activity must be great enough to overcompensate for the increase in concentration of protonated species with increasing acidity. The case thus does not strictly parallel that of amides.

Aryloxyphosphonium salts. The new chemistry discussed here relates to studies with aryloxyphosphonium salts. These salts serve as models for protonated esters; that is to say, the cation, $\mathrm{CH}_{3} \mathrm{P}\left(\mathrm{OC}_{8} \mathrm{H}_{5}\right)_{3}^{+}$, should serve as a model for $\mathrm{CH}_{3} \mathrm{P}\left(\mathrm{OC}_{6} \mathrm{H}_{5}\right)_{2} \mathrm{OH}^{+}$; the latter in turn is the protonation product of diphenyl methylphosphonate.

$$
\mathrm{CH}_{3} \mathrm{P}\left(\mathrm{OC}_{6} \mathrm{H}_{5}\right)_{2} \mathrm{O}+\mathrm{H}^{+} \rightleftharpoons \mathrm{CH}_{3} \mathrm{P}\left(\mathrm{OC}_{6} \mathrm{H}_{5}\right)_{2} \mathrm{OH}^{+}
$$

In our previous communication (19), we proposed a mechanism for the hydrolysis of aryloxyphosphonium salts and of aryl phosphates. Further investigation has now shown that the mechanisms previously advanced cannot be completely correct, and may in fact be seriously in error. At the present time, we are unable to specify the hydrolytic mechanism with confidence. Nevertheless, some alternatives can be examined, and tentative conclusions reached. In any event, the chemistry of the aryloxyphosphonium salts, as it develops, should help elucidate that of the aryl phosphates.

Compounds such as $\mathrm{CH}_{3} \mathrm{P}\left(\mathrm{OC}_{6} \mathrm{H}_{6}\right)_{3}^{+}, \mathrm{CF}_{3} \mathrm{SO}_{3}^{-}$undergo rapid hydrolysis. The rate in acetonitrile increases more or less with the third power of the water content of the solvent, and exceeds the limits of the stopped-flow apparatus (i.e. $\mathrm{k}>1000 \mathrm{sec}^{-1}$ ) at about $8 \%$ water. However, the hydrolysis of methyltri(2, 6-dimethylphenoxy) phosphonium ion can be followed up to $60 \%$ water, where the rate levels off. Since the effect of water on the hydrolyses of the two salts is similar, a reasonable extrapolation of the rate of hydrolysis of the methyltriphenoxyphosphonium salt to high water concentration can be made. The appropriate graphical presentation of the data is given in Figs. 1 and 2 (19).

Whatever the mechanism of hydrolysis of the aryloxy salt, the same mechanism should obtain, with (perhaps) a similar rate constant, for the hydrolysis of the protonated ester. In the region of acidity where the phosphate ester is only slightly protonated, the rate of hydrolysis of the ester should be proportional to the hydrogen ion concentration (or to some other acidity function).

Under these conditions, and almost regardless of mechanism, if the rate constant for the hydrolysis of the protonated ester is the same as that for the corresponding aryloxy salt, then we expect that 


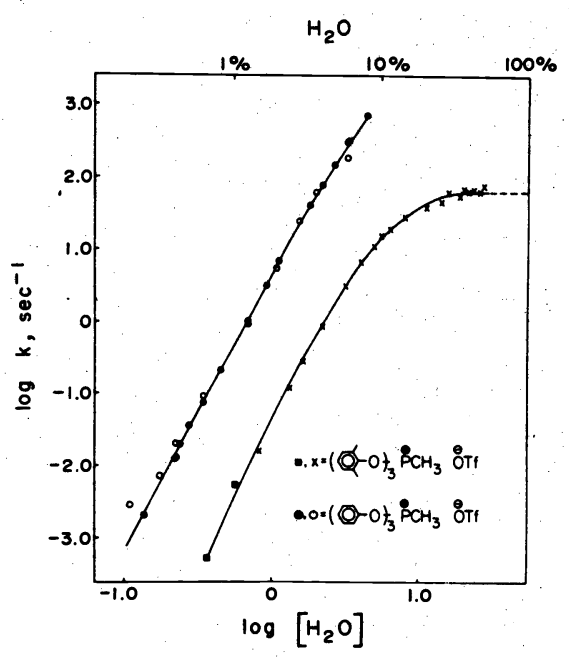

Fig. 1 Rate constants in inverse seconds for the hydrolysis of methyltriphenoxyphosphonium triflate and of methyl tri(2,6-dimethylphenoxy)phosphonium triflate at $25^{\circ}$. Open circles and X's: measurements with a Durham-Gibson stopped-flow apparatus; filled circles and squares: measurements with a Cary 15 spectrophotometer. (Reprinted with permission from J. Amer. Chem. Soc. )

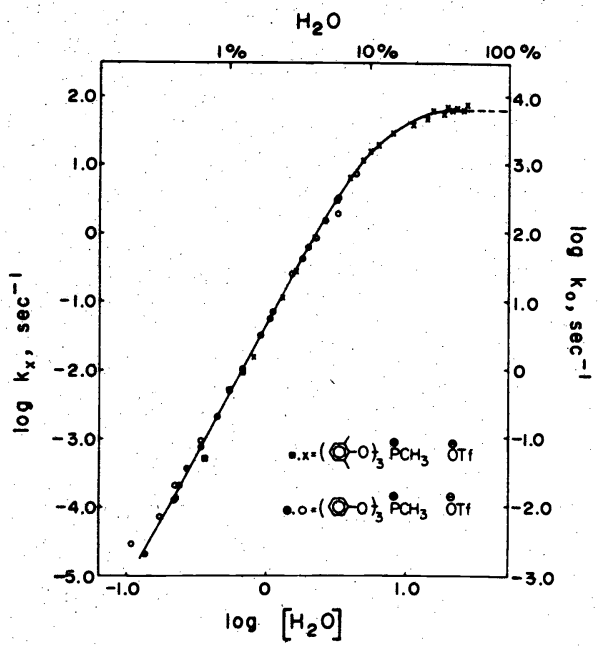

Fig. 2 Rate constants in inverse seconds for the hydrolysis of methyltriphenoxyphosphonium triflate (right-hand scale) and for the hydrolysis of methyltri(2, 6-dimethylphenoxy)phosphonium triflate (left-hand scale), at $25^{\circ}$. (Reprinted with permission from J. Amer. Chem. Soc.)

$$
\mathbf{k}^{\text {ester }}=\mathbf{k}^{\text {salt }}\left(\mathrm{H}^{+}\right) / \mathrm{K}_{1}
$$

(It will be shown later that this equation does not lead to a good approximation for $\mathrm{k}^{\text {ester }}$, and the assumptions underlying the model will be reexamined.)

Effect of triflic acid. The rates of the hydrolyses drop sharply with increase in acid concentration. The data for the two salts in $6 \%$ water - $94 \%$ acetonitrile and for the sterically hindered salt in $34 \%$ water $-66 \%$ acetonitrile are shown below. The rate falls off with something like the 3.6 th power of the concentration of added triflic acid (19).

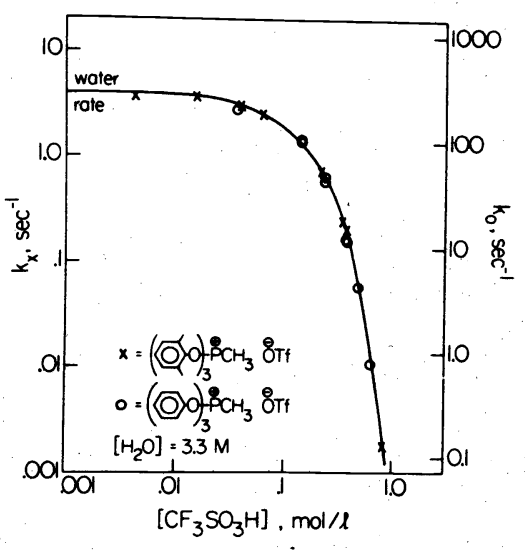

Fig. 3 Rate constants in inverse seconds for the hydrolysis of methyltriphenoxyphosphonium triflate (right hand scale) and for the hydrolysis of methyltri(2,6-dimethylphenoxy)phosphonium triflate (left hand scale) in $6 \%$ aqueous acetonitrile at $25^{\circ}$. (Reprinted with permission from J. Amer. Chem. Soc.)

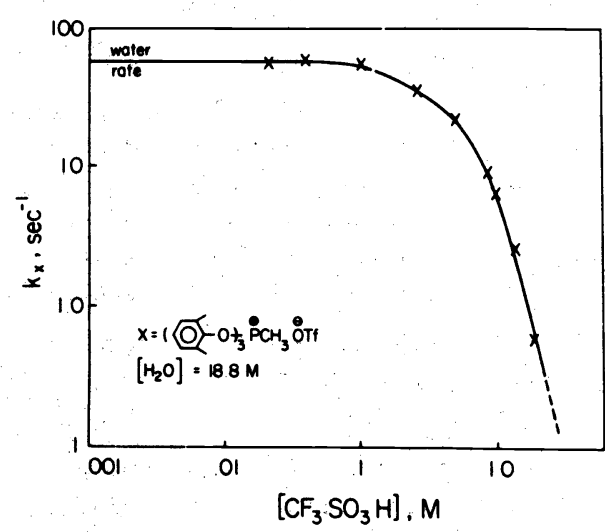

Fig. 4 Rate constants in inverse seconds for the hydrolysis of methyltri(2,6-dimethylphenoxy)phosphonium triflate, in $34 \%$ aqueous acetonitrile as solvent. (Reprinted with permission from J. Amer. Chem. Soc.) 
When $\mathrm{k}^{\text {salt }}\left(\mathrm{H}^{+}\right)$is plotted against hydrogen-ion concentration (in accordance with eq. [1]) a curve with approximately the correct shape is obtained but the rate maximum occurs at about $0.6 \mathrm{M}$ acid, instead of at about $1.8 \mathrm{M}$ acid, as observed for the hydrolysis of triphenyl phosphate; the two curves are shown together in Fig. 5.

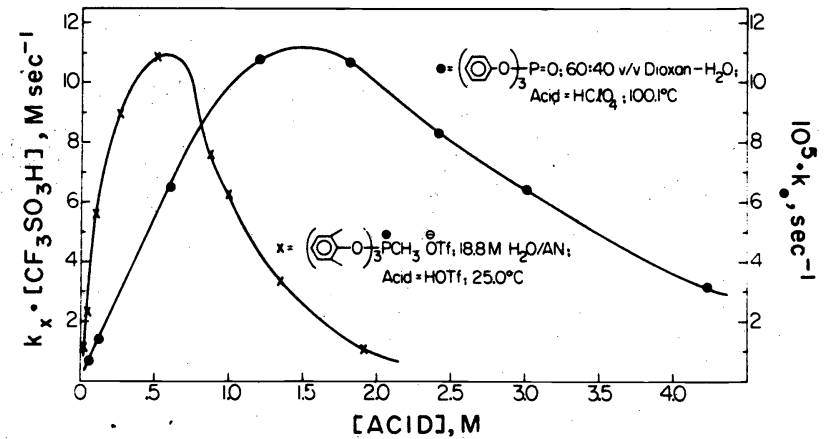

P. W. C. Bornard, C. A. Bunton, D. Kellerman, M.M. Mholo, B. Silver.

C. A. Vernon, V. A. Welch, J. Chern. Soc.(B), 1966, 227.
Fig. 5 pH-rate profile for the hydrolysis of triphenylphosphate (after Barnard et al. (14) and calculated by eq. (1) from the data for the hydrolysis of methyltri(2, 6-dimethylphenoxy)phosphonium triflate.

However, when the absolute rate for the hydrolysis of the ester is calculated from equation (1), the calculated rate exceeds that observed (note a) by a large factor, probably about 1,000. The determination of this factor depends, of course, on the $\mathrm{pK}$ of -5 assigned to the conjugate acid of triphenyl phosphate $(16,18)$. This value may not be the appropriate one to use; as Arnett $(20)$ has pointed out, the particular acidity function chosen in any specific example should be measured with indicators similar in structure to the substrate. Further problems arise because different solvents have been used in different investigations. But if (as seems probable) a large discrepancy still exists when these factors have been properly taken into account, then some further explanation must be sought; a possible explanation is presented later.

The hydrolysis of aryloxyphosphonium salts is subject to an unusually large salt effect. The rate constant for the hydrolysis of methyltri(2,6-dimethylphenoxy)phosphonium triflate in $66 \%$ acetonitrile $34 \%$ water is only about $1 / 30$ as great in the presence of $1.8 \mathrm{M}$ lithium triflate as in its absence. Further, triflic acid is much less effective in decreasing the rate of hydrolysis of this phosphonium cation at constant high ionic strength (Fig. 6) than in the absence of salt (Fig. 4). Moreover, since the additional effect of acid, over and beyond that of salt, is relatively small, the possibility remains open that the apparent effect of acidity at high ionic strength is an artifact, arising from a difference in salt effects between triflic acid and lithium triflate. In our previous publication (19), we had suggested that, at high acid concentration, the rates of hydrolysis of our aryloxyphosphonium salts vary inversely as the second power of the acidity. The new data show that this is not correct. A major part, and perhaps all of the diminution in rate in the presence of acid is probably caused by a diminution in the availability of water, sequestered by the added salts or acid; this is the explanation previously advanced by Haake (14) and Bunton (15) for the rate maximum in the hydrolysis of aryl phosphates and phosphonates.

But how can one explain a diminution in rate of hydrolysis by a factor of 30 caused by only $1.8 \mathrm{M}$ salt? Jordan has suggested (22) that the acidity of solutions in aqueous acetonitrile can be estimated by calculating the concentration of acid as if the acetonitrile were not present. In other words, $1.8 \mathrm{M}$ lithium triflate in $34 \%$ aqueous acetonitrile may be the equivalent of $5.4 \mathrm{M}$ lithium triflate in water. At such high concentrations, a large salt effect becomes reasonable, although a factor of 30 is still large even compared to the effect of high concentration of salt on $\mathrm{H}_{\mathrm{o}}(23)$.

If this line of thinking is correct, why then does $2.4 \mathrm{M}$ salt diminish the rate of hydrolysis of triphenyl phosphate in $60 \%$ dioxane - $40 \%$ water by a factor of only 2.4 ? Possibly the difference lies in the

Note a. The rate constant originally reported for the acid-catalyzed hydrolysis of diphenyl methylphosphonate (21) is less than that for triphenyl phosphate by a factor of about 100. More recently, however, Professor Hudson ( $2 \mathrm{lb}$ ) has informed us, in a private communication, that the correct rate constant for the hydrolysis of this ester at $110^{\circ}$ in $60 \% \mathrm{DME}-40 \%$ water in the presence of $1 \underline{\mathrm{M}}$ triflic acid is $4.15 \times 10^{-5} \underline{\mathrm{M}}^{-1} \mathrm{sec}^{-1}$, quite comparable to the corresponding rate constant for the hydrolysis of triphenyl phosphate. 
solvent; dioxane may coordinate cations well enough to "protect" the water, whereas acetonitrile does not. But possibly the relatively modest diminution in rate of hydrolysis of the ester in the presence of salt arises in part as the resultant of two opposing effects: an increase in the concentration of protonated ester caused by a decrease in $\mathrm{H}_{0}$ in salt solutions (23), coupled with a large decrease in the rate of hydrolysis of the cations similar to that found here for aryloxyphosphonium salts.

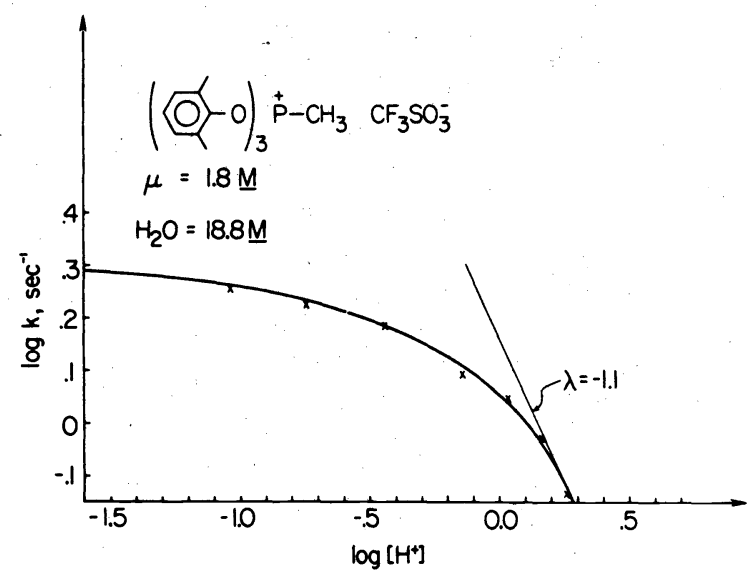

Fig. 6 Rate constants in inverse seconds for the hydrolysis of methyltri(2, 6-dimethylphenoxy)phosphonium triflate in aqueous acetonitrile at an ionic strength of 1.8 M.

Scheme I shows a mechanism for the hydrolysis of aryloxyphosphonium salts that leads to equation (2).

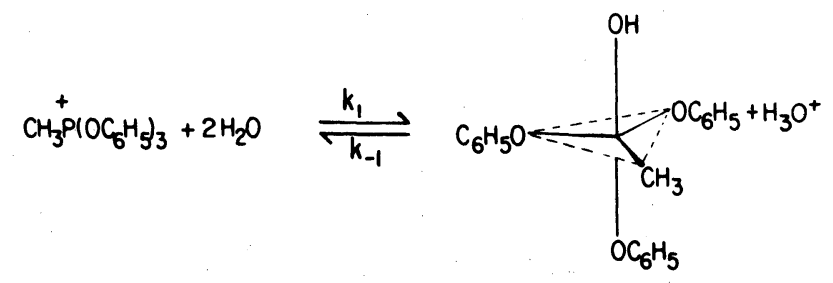

$$
\begin{aligned}
& \begin{array}{c}
\left\lfloor k_{2}\right. \\
\mathrm{C}_{6} \mathrm{H}_{5} \mathrm{OH}+\mathrm{CH}_{3} \stackrel{0}{\stackrel{\prime \prime}{P}}\left(\mathrm{OC}_{6} \mathrm{H}_{5}\right)_{2}
\end{array} \\
& k^{\text {salt }}=\frac{k_{1} k_{2}\left(\mathrm{H}_{2} \mathrm{O}\right)^{2}}{k_{2}+k_{-1}\left(\mathrm{H}_{3} \mathrm{O}^{+}\right)}
\end{aligned}
$$

Equation 2 leads to the conclusion that, at low acidity, the addition of water to the phosphonium salt is rate limiting; further, the addition of water might prove rate limiting at all reasonable acid concentrations, since the data are not yet available (note $b$ ) to evaluate the relative values of $k_{-1}$ and $k_{2}$. If this scheme is correct, then a parallel mechanism (preceded, of course, by protonation of the ester) applies to ester hydrolysis. The postulated hydroxyphosphorane (25) has already been shown to decompose rapidly, although the details of the mechanism have not yet been elucidated. Further, in the event that the decrease in rate at high acidity proves significant, and not an artifact, equation (2)

Note b. The rate constant for the ionization of methyltetraphenoxyphosphorane in acetonitrile at $25^{\circ}$ is $7.5 \mathrm{sec}^{-1}(24)$; this sets a lower limit for $k_{2}$, but the value for the hydroxyphosphorane in the more polar solvent may be substantially higher. 
would accommodate the data.

Despite some attractive features, Scheme I coupled with equation (1) has major defects. First, as previously noted, the absolute rate constant, calculated on the basis of the assumption that an aryloxyphosphonium salt is a good model for the corresponding protonated ester, is about 1000 times as great as that observed in acid for the hydrolysis of triphenyl phosphate or for diphenyl methylphosphonate. Perhaps the uncertainty in the $\mathrm{pK}$ of triphenyl phosphate (see above) is important, or the differences in solvent are significant. Perhaps, however, the phenoxy group is not a good surrogate for the hydroxyl group. Both because the hydroxyl group can accommodate positive charge better than a phenoxy group, and because the former will be hydrogen bonded to the solvent, it may drain more of the positive charge from phosphorus than the latter. A less electropositive phosphorus atom would hydrate less rapidly. Whether such an effect is large enough to account for the observed rate ratio cannot yet be decided.

A second defect is that the kinetic scheme requires that, at high acidity, the addition of water to an aryloxyphosphonium salt, or to a protonated ester, be reversible. This requirement would at first giance seem to demand that oxygen exchange into the ester accompany acid-catalyzed hydrolysis, whereas Bunton and Farber (16) found that very little oxygen exchange accompanies the hydrolysis of triphenyl phosphate in $0.5 \mathrm{M}$ acid at $100^{\circ}$ in $75 \%$ dioxane $-25 \%$ water. But of course if the ratelimiting step in the hydrolysis (according to Scheme I) is the addition of water to the phosphonium cation, subsequent steps would occur too rapidly to permit oxygen exchange. Even if it should develop that the apparent inhibition by acid, shown in Fig. 6, is mechanistically important, oxygen exchange still need not accompany hydrolysis. If, in the mechanism here suggested, the phenoxy group is very much more apicophilic than the hydroxyl group, then pseudorotation would be required for oxygen exchange, but not for ester hydrolysis. In the dihydroxyphosphorane formed as an intermediate, one hydroxyl group is apical and one equatorial; only the apical one will protonate, and pseudorotation is required to make the two equivalent. Pseudorotation, although rapid, has proved rate-limiting in other cases (26). Quite obviously, the mechanism will have to be much more firmly established before such subtle effects are worth consideration.

Finally, it must be admitted that Scheme $I$ is not the only mechanistic pathway consistent with the experimental data. On the assumption that the diminution of rate with increasing acid concentration at constant ionic strength is an artifact, a mechanism that ejects phenol from the cations,

$$
\begin{gathered}
\mathrm{CH}_{3}-\mathrm{P}(\mathrm{OH})\left(\mathrm{OC}_{6} \mathrm{H}_{5}\right)_{2} \\
\mathrm{H}-\mathrm{OC}_{6} \mathrm{H}_{5} \\
+{ }^{2}
\end{gathered}
$$

$$
\begin{gathered}
\mathrm{CH}_{3}-\mathrm{P}(\mathrm{OH})_{2} \mathrm{OC}_{6} \mathrm{H}_{5} \\
\mathrm{H}-\mathrm{OC}_{6} \mathrm{H}_{5} \\
+
\end{gathered}
$$

would also fit the data for the hydrolysis of the aryloxyphosphonium salt and those for the corresponding phosphonate ester. In fact, even a mechanism that involves a displacement by water from the cations could be considered. Such a mechanism would necessarily be concerted with proton transfer, to yield hydronium ion, a phosphonium ion and phenolate ion; unless it were concerted, the product would violate the adjacent charge rule. While these latter mechanisms appear relatively unlikely, with the evidence at hand they cannot be positively excluded. Although many problems of the hydrolysis of the aryl phosphates are still unsolved, investigations of the chemistry of the aryloxyphosphonium salts should enhance and facilitate the determination of mechanism.

\section{MONOMERIC METAPHOSPHATES}

The hydrolysis of sterically hindered carboxylic acids in strong acid may take place by way of acylium ions. These highly electrophilic ions were first detected by cryoscopic measurements in sulfuric acid solution (4), but subsequently these and other carbonium ions were seen in $\mathrm{nmr}$ spectroscopy by Deno (5) and Olah (6) and their collaborators.

The comparable chemistry of phosphate esters takes place by way of the strongly electrophilic monomeric metaphosphate ion and the corresponding esters. The anion, $\mathrm{PO}_{3}^{-}$, was postulated twenty years ago on the basis of kinetic evidence (27). Subsequently a number of other studies $(28,29)$ strongiy suggested monomeric metaphosphates in the hydrolysis of certain phosphate esters. The nitrogen analogs of monomeric metaphosphates, the monomeric metaphosphorimidates, were also postulated (30) as intermediates in the hydrolysis of phosphoramidic halides. Since these hydrolyses proceed as much as $10^{8}$ times as rapidly when a hydrogen atom is attached to an amide nitrogen atom as when the nitrogen atoms are fully substituted (31), reaction via metaphosphorimidates seemed indicated (32), e.g. 


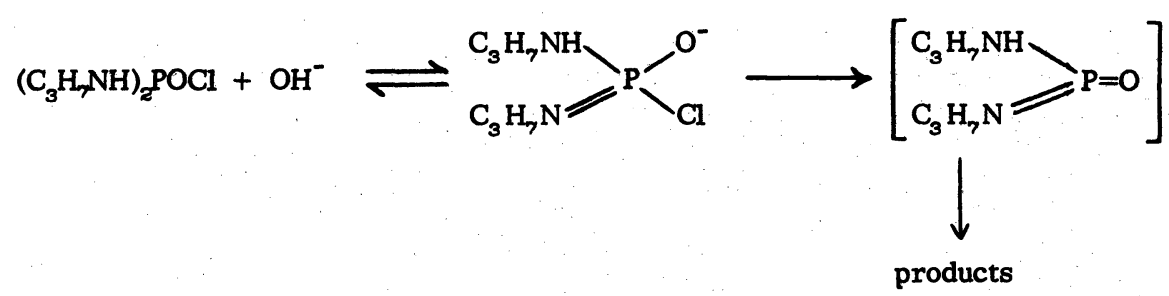

The postulate of monomeric metaphosphorimidates has also been supported by stereochemical evidence (33), and by the preparation of silylated imidates (34) such as $\left(\mathrm{CH}_{3}\right)_{3} \mathrm{Si}-\mathrm{N}=\mathrm{P}\left[\mathrm{NSi}\left(\mathrm{CH}_{3}\right)_{3} \mathrm{l}_{2}\right.$ and of analogous alkylideneoxyphosphoranes.

Three phase test. Recently two other methods of preparing and/or observing monomeric metaphosphates have been reported: the three-phase test, introduced by J. Rebek (35) and the pyrolysis of phosphonates from our laboratory (36).

Rebek has attached to one type of polymer beads a compound that is expected to decompose to a monomeric metaphosphate, and a possible receptor to another type of beads. The beads are then mixed in a solvent (dioxane) and treated with a catalyst needed to produce the unstable intermediate. Transfer of the monomeric metaphosphate or metaphosphorimidate from one bead to another cannot occur by way of a bimolecular reaction, and therefore requires the transfer of an unstable intermediate through the solvent. When a fully substituted phosphoramidate (i.e. with no ionizable hydrogen atom) is attached to the polymer beads, no phosphorimidate can be formed, and no reaction occurs. Rebek has also demonstrated $\mathrm{PO}_{3}^{-}$by the three phase test.

Pyrolysis. The pyrolysis of methyl butenylphosphonate yields butadiene and monomeric methyl metaphosphate (36).<smiles>C=CC=CCOCCOC</smiles>

The pyrolysis is carried out at about $600^{\circ}$ and $20 \mu$ pressure of inert gas, with a contact time of the order of a few hundredths of a second. The product gases impinge on the surface of a stirred solution of some trapping agent dissolved in butyl benzene at $-80^{\circ}$. Monomeric methyl metaphosphate was first trapped with $\mathrm{N}$-methylaniline to yield compound $\mathrm{A}$.

A more significant test comes from the reaction of monomeric methyl metaphosphate with diethylaniline, which results in electrophilic substitution into the aromatic ring to yield $B$.<smiles>CO[P+](=O)[NH2+]c1ccccc1</smiles>
A.

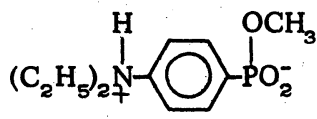
B.

The formation of the electrophilic substitution product serves to identify monomeric metaphosphates.

The pyrolysis technique has also been used to make phosphonobenzene, $\mathrm{C}_{6} \mathrm{H}_{5} \mathrm{PO}_{2}$, and phosphonomesitylene. Pyrolysis of methyl ethylene phosphite produces monomeric methyl metaphosphate, along with ethylene.

The evidence for the existence of monomeric metaphosphate is then comparable to that for the existence of acylium ions. Kinetic evidence is always required, however, to decide whether monomeric metaphosphates participate in specific chemical or biochemical processes. 
Acknowledgements. The umpublished work from our laboratory here described was carried out by Mr. Steven Kubisen, Jr., and by Dr. Arnold Satterthwait. Our research has been supported by the National Science Foundation under grant number MPS 7417595. The author wishes to thank Dr. A. J. Kirby (University of Cambridge) for useful discussions.

\section{REFERENCES}

1. G. E. Lienhard and W. P. Jencks, J. Amer. Chem. Soc. 87, 3855-3874 (1965); W. P. Jencks, Catalysis in Chemistry and Enzymology, pp. 81-83, 103-105, 112-115, McGraw-Hill, New York (1969).

2. M. L. Bender, Chem. Rev. 60, 53-113 (1960); S. A. Shain and J. F. Kirsh, J. Amer. Chem. Soc. 90, 5848-5854 (1968).

3. A. J. Kirby, Comprehensive Chemical Kinetics 10, 57-207 (1972); H. E. Zaugg, V. Papendick and R. J. Michaels, J. Amer. Chem. Soc. 86, 1399-1402 (1964); B. A. Cunningham and G. L. Schmir, J. Amer. Chem. Soc. 88, 55 1-558 (1966).

4. L. P. Hammett and A. J. Deyrup, J. Amer. Chem. Soc. 55, 1900-1909 (1933); H. P. Treffers and L. P. Hammett, J. Amer. Chem. Soc. 59, 1708-1714 (1937); R. J. Gillespie and J. H. Leisten, Quart. Rev. (London) 8, 40-66 (1954).

5. N. C. Deno, C. U. Pittman, Jr. and M. J. Wisotsky, J. Amer. Chem. Soc. 86, 4370-4372 (1964).

6. G. A. Olah and A. M. White, J. Amer. Chem. Spc. 89, 3591-3594(1967); G. A. Olah and A. M. White, J. Amer. Chem. Soc. 89, 7072-7075 (1967); G. A. Olah, W. S. Tolgyesi, S. J. Kuhn, M. E. Moffatt, I. J. Bastien and E. B. Baker, J. Amer. Chem. Soc. 85, 1328-1334 (1963); G. A. Olah, S. J. Kuhn, W. S. Tolgyesi and E. B. Baker, J. Amer. Chem. Soc. 84, 2733-2740 (1962).

7. E. A. Dennis and F. H. Westheimer, J. Amer. Chem. Soc. 88, 3431; 3432-3433 (1966); F. H. Westheimer, Accounts Chem. Res. 1, 70-78 (1968).

8. F. Covitz and F. H. Westheimer, J. Amer. Chem. Soc. 85, 1773- 1777 (1963).

9. A. Eberhard and F. H. Westheimer, J. Amer. Chem. Soc. 87, 253-260 (1965).

10. J. R. Cox, Jr. and F. H. Westheimer, J. Amer. Chem. Soc. 80, 5441-5443 (1968); E. T. Kaiser, M. Panar and F. H. Westheimer, J. Amer. Chem. Soc. 85, 602-607 (1963); J. M. Sturtevant, J. A. Gerlt and F. H. Westheimer, J. Amer. Chem. Soc. 95, 8168-8169 (1973).

11. E. L. Muetterties and R. A. Schwinn, Quart. Rev. (London) 20, 245-299 (1965).

12. R. K. Oram and S. Trippett, J. Chem. Soc., Perkin Trans. I, 1300-1301 (1973).

13. S. J. Benkovic and E. J. Sampson, J. Amer. Chem. Soc. 93, 4009-4016 (1971); D. S. Frank and D. A. Usher, J. Amer. Chem. Soc. 89, 6360-6361 (1967); D. Gay and N. Hamer, J. Chem. Soc. B, $1123-1127$ (1970); D. Gay and N. Hamer, J. Chem. Soc., Perkin Trans. II, 929-932 (1972); $\bar{K}$. L. Marsi, J. Amer. Chem. Soc. 91, 4724-4729 (1969); K. E. DeBruin, G. Zon, K. Naumann and K. Mislow, J. Amer. Chem. Soc. 91, 7027-7030 (1969); K. E. DeBruin, A. G. Padilla and M. T. Campbell, J. Amer. Chem. Soc. 95, $4681-4687$ (1973); K. Mislow, Accounts Chem. Res. 3, 321-331 (1970); D. G. Gorenstein, J. Amer. Chem. Soc. 94, 2808-2814 (1972).

14. P. Haake and G. Hurst, J. Amer. Chem. Soc. 88, 2544-2550 (1966).

15. P. W. C. Barnard, C. A. Bunton, D. Kellerman, M. M. Mhala, B. Silver, C. A. Vernon and V. A. Welch, J. Chem. Soc. B, 227-233 (1966); C. A. Bunton, E. J. Fendler and J. H. Fendler, J. Amer. Chem. Soc. 89, 1221- 1230 (1967); C. A. Bunton, S. J. Farber and E. J. Fendler, J. Org. Chem. 33, 29-33 (1968).

16. C. A. Bunton and S. J. Farber, J. Org. Chem. 34, 3396-3403 (1969).

17. J. T. Edward and S. C. R. Meacock, J. Chem. Soc., 2000-2007, 2009-2012 (1957); J. F. Bunnett, J. Amer. Chem. Soc. 83, 4956-4967(1961); C. A. Bunton, D. O'Connor and T. A. Turney, Chem. Ind., 1835-1836 (1967); C. L. Smith and K. Yates, J. Amer. Chem. Soc. 93, 6578-6583 (1971); K. Yates and R. A. McClelland, J. Amer. Chem. Soc. 89, 2686-2692 (1967).

18. P. Haake, R. D. Cook and G. H. Hurst, J. Amer. Chem. Soc. $\overrightarrow{89}, 2650-2654$ (1967).

19. C. M. Lonzetta, S. J. Kubisen, Jr. and F. H. Westheimer, J. Amer. Chem. Soc. 98, 1632-1634 (1976); S. J. Kubisen, Jr., Unpublished.

20. E. M. Arnett, Prog. Phys. Org. Chem. 1, 223-403 (1964).

21. (a) R. F. Hudson and L. Keay, J. Chem. Soc., 2463-2469 (1956); (b) R. F. Hudson, private communication 7-14-76.

22. F. Jordan, I. Phys. Chem. 77, $2681-2683$ (1973).

23. M. A. Paul and F. A. Long, Chem. Rev. 57, 1-45 (1957); J. P. H. Boyer, R. J. P. Corriu and R. J. M. Perz, Tetrahedron 27, 4334-434 $1,5255-5270$ (1971).

24. D. Phillips, I. Szele and F. H. Westheimer, J. Amer. Chem. Soc. 98, 185- 189 (1976).

25. W. C. Archie, Jr. and F. H. Westheimer, J. Amer. Chem. Soc. 95, 5955-5959 (1973).

26. R. Kluger and F. H. Westheimer, J. Amer. Chem. Soc. 91, 4143-4150 (1969); R. Kluger, F. Covitz, E. Dennis, L. D. Williams and F. H. Westheimer, J. Amer. Chem. Soc. 91, 6066- 
6072 (1969); D. G. Gorenstein, J. Amer. Chem. Soc. 94, 2808-2814 (1972).

27. W. W. Butcher and F. H. Westheimer, J. Amer. Chem. Soc. 77, 2420-2424 (1955); D. W. C. Barnard, C. A. Bunton, D. R. Llewellyn, D. G. Oldham, B. L. Silver and C. A. Vernon, Chem. Ind. (London), 760-763 (1955).

28. A. R. Todd, Proc. Nat. Acad. Sci. U.S.A. 45, 1389-1397 (1959); G. DiSabato and W. P. Jencks, J. Amer. Chem. Soc. 83, 4400-4405 (1961); A. J. Kirby and W. P. Jencks, J. Amer. Chem. Soc. 87, 3209-3216 (1965); G. L. Kenyon and F. H. Westheimer, J. Amer. Chem. Soc. 88, 3561$\overline{3565}$ (1966); A. J. Kirby and A. G. Varvoglis, J. Amer. Chem. Soc. 89, 415-423 (1967); P. Haake and P. S. Ossip, J. Amer. Chem. Soc. 93, 6924-6930 (1971); D. G. Gorenstein, J. Amer. Chem. Soc: 94, 2523-2525 (1972); D. B. Trowbridge, D. M. Yamamoto and G. L. Kenyon, J. Amer. Chem. Soc. 94, 3816-3824 (1972); R. Kluger, J. Org. Chem. 38, 2721-2722 (1973).

29. D. M. Brown and N. K. Hamer, J. Chem. Soc., 1155-1161 (1960); D. Samuel and B. Silver, J. Chem. Soc., 4321-4324 (1961).

30. F. H. Westheimer, Chem. Soc. Spec. Publ. $8,181-182$ (1957).

31. D. F. Heath, J. Chem. Soc., 3796-3803, 3804-3809 (1956).

32. P. S. Traylor and F. H. Westheimer, J. Amer. Chem. Soc. 87, 553-557 (1965); E. W. Crunden and R. F. Hudson, Chem. Ind. (London), 1478-1479 (1958); E. W. Crunden and R. F. Hudson, J. Chem. Soc., 3591-3599(1962); D. Samuel and F. H. Westheimer, Chem. Ind. (London), 51 (1959); M. A. H. Fahmy, A. Khasawinah and T. R. Fukuto, J. Org. Chem. 37, 617-625 (1972); H. K. Hall, J. Org. Chem. 21, 248-249 (1956); A. Williams and K. T. Douglas, J. Chem. Soc., Perkin Trans. II, 1454-1459 (1972); A. Williams and K. T. Douglas, J. Chem. Soc., Perkin Trans. II, 318-324 (1973).

33. A. F. Gerrard and N. K. Hamer, J. Chem. Soc. B, 539-543 (1968); A. F. Gerrard and N. K. Hamer, J. Chem. Soc. B, 1122-1125(1967); J. Wiseman and F. H. Westheimer, J. Amer. Chem. Soc. 96, 4262-4268(1974).

34. E. Niecke and W. Flick, Angew. Chem. Intern. Ed. Eng. 13, 134-135 (1974); O. J. Scherer and N. K. Kuhn, Chem. Ber. 107, 2123-2125 (1974); N. T. Kulbach and O. J. Scherer, Tetrahedron Lett., 2297-2298(1975); $\bar{M}$. Regitz, H. Scherer, W. Illger and H. Eckes, Angew. Chem. Intern. Ed. Eng. 12, 1010-1011 (1973); M. Regitz, A. Liedhegener, W. Anschutz and H. Eckes, Chem. Ber. 104, 2177-2194 (1971); M. Regitz, H. Scherer and W. Anschutz, Tetrahedron Lett., 753$\overline{756}(\overline{1970})$.

35. J. Rebek and F. Gavina, J. Amer. Chem. Soc. 97, 1591-1594 (1975); J. Rebek and F. Gavina, J. Amer. Chem. Soc. 97, 3221-3222 (1975).

36. C. H. Clapp and F. H. Westheimer, J. Amer. Chem. Soc. 96, 6710-6714 (1974); C. H. Clapp, A. Satterthwait and F. H. Westheimer, J. Amer. Chem. Soc. 97, 6873-6874 (1975). 